TITLE:

\title{
The effects of prenatal and postnatal environmental interaction: Prenatal environmental adaptation hypothesis.
}

\author{
$\operatorname{AUTHOR}(\mathrm{S})$ : \\ Lee, Young-A; Goto, Yukiori
}

\section{CITATION:}

Lee, Young-A ... [et al]. The effects of prenatal and postnatal environmental interaction: Prenatal environmental adaptation hypothesis.. Journal of physiology, Paris 2013, 107(6): 483-492

\section{ISSUE DATE:}

2013-12

URL:

http://hdl.handle.net/2433/179781

\section{RIGHT:}

(c) 2013 Elsevier Ltd.; この論文は著者最終稿です。内容が印刷版と異な ることがありますので、引用の際には出版社版をご確認ご利用くださ $\omega_{\circ}$ This is the Accepted Author Manuscript. Please cite only the published version. 


\section{The Effects of Prenatal and Postnatal Environmental Interaction: Prenatal Environmental Adaptation Hypothesis}

Running title: Prenatal environmental adaptation

Young-A Lee \& Yukiori Goto*

Primate Research Institute, Kyoto University, Aichi, Japan

Address Correspondence:

Yukiori Goto, Ph.D.

Kyoto University Primate Research Institute

Cognition \& Learning Section

41-2 Kanrin, Inuyama

Aichi 484-8506

Japan

Phone: +81(568)63-0551

Fax: +81(568)63-0551

E-mail: goto.yukiori.5c@kyoto-u.ac.jp

Pages: 40 pages

Abstract: 133 words

Text: 7,020 words

References: 175

Figures: 0

Tables: 0 


\begin{abstract}
Adverse antenatal maternal environments during pregnancy influence fetal development that consequently increases a risk of mental health problems including psychiatric disorders in offspring. Therefore, behavioral and brain alterations caused by adverse prenatal environmental conditions are generally considered as deficits. In this article, we propose a novel hypothesis, along with summarizing a body of literatures supporting it, that fetal neurodevelopmental alterations, particularly synaptic network changes occurring in the prefrontal cortex, associated with adverse prenatal environmental conditions may be adaptation to cope with expected severe postnatal environments, and therefore, psychiatric disorders may be able to be understood as adaptive strategies against severe environmental conditions through evolution. It is hoped that the hypothesis presented in this article stimulate and open a new venue on research toward understanding of biological mechanisms and therapeutic treatments of psychiatric disorders.
\end{abstract}

Key words: Evolution; Neurodevelopment; Prefrontal cortex; Hippocampus; Synaptic network; microRNA; Psychiatric disorder; Epigenetics; Cognitive function 


\section{Introduction}

Extensive investigation has now unveiled that antenatal maternal environments during pregnancy substantially influences fetal brain development that could ultimately cause mental health problems in offspring. Epidemiological studies have shown that prenatal exposure to adverse environmental factors such as stress, famine, and virus infection, is associated with increased risks of psychiatric disorders such as schizophrenia, attention deficit/hyperactivity disorder (ADHD), and autism in offspring (Malaspina et al., 2008; Rice et al., 2010; Kinney et al., 2008; Ronald et al., 2011; van Os and Selten, 1998; Rodriguez and Bohlin, 2005; Khashan et al., 2008; Brown et al., 1995a; Brown et al., 2000; Susser et al., 1996; Favaro et al., 2011; Mednick et al., 1988; Brown et al., 1995b; Brown, 2006; Machon et al., 1997).

It is generally agreed that behavioral and brain changes caused by prenatal exposure to adverse environmental conditions are “deficits”, “impairments”, and “abnormalities”. However, this doctrine may be challenged by the following two apprehensions. First, the fetal brain is likely to be highly plastic. For instance, even in the adult brain in which plasticity, an ability of the system to be modulated by experience and environments, would be more limited than that in the fetal brain, the plasticity mechanism try to recover damages caused by stroke or ischemia (Kolb and Whishaw, 1998; Hallett, 2001; Hosp and Luft, 2011). If there is any defect in the process of brain development, plasticity mechanism should overcome such a deficit. Nevertheless, studies have found no trace of any compensatory action that correct a deficit, interruption, or deviation of fetal brain development incurred by prenatal exposure to environmental insults. This provokes a question of why the highly dynamic plasticity mechanism in the fetal brain does not fix developmental changes that produce unfavorable consequences. Second, if maternal exposure to environmental insults yields negative influences 
on fetal development, why does the biological system has to be existent that deliberately transmits adverse environmental information from mothers to fetuses that produces unfavorable changes in fetuses? Existence of such an unfavorable system is especially inexplicable from the evolutionary biological perspective.

One possible answer to the above questions is a hypothesis that fetal developmental changes caused by prenatal exposure to environmental insults are not deficits, but adaption to prepare for expected severe environmental conditions after birth. Indeed, we usually consider prenatally-induced alterations as deficits in a daily postnatal environmental condition (the environmental condition that the majority of lifetime is spent). In contrast, we have missed to consider how prenatally-induced changes could fit into a rather unusual postnatal environmental condition.

The idea that fetal developmental alterations with adverse prenatal environmental conditions may be adaptation to prepare for postnatal severe environments is, although barely considered in the field of neuroscience, in fact not a new, but it has been originally proposed by the UK medical scientist, David Barker, and therefore known as Barker hypothesis. The finding that led him to propose the hypothesis is a significant association between low birth weight and adverse adult health outcomes such as coronary heart disease and diabetes (Barker, 1997; Godfrey and Barker, 2000). This observation can be explained as following. Thus, low birth weight in fetuses may indicate insufficient nutrition during pregnancy. To cope with low nutrition, fetal metabolism is lowered to conserve more energy. However, when such offspring with low metabolism is exposed to adequate nutrient after birth, it results in abnormally excessive energy conservation and consequently causes health problems. Increasing empirical 
evidence has now supported this hypothesis (for instance, see review papers such as Lumey et al, 2011, for the summary of research supporting the Barker hypothesis).

\section{Prenatal stress as environmental adaptation}

\subsection{Effects of prenatal stress in humans}

A huge body of literatures has unveiled the effects of prenatal stress on fetal development and consequent postnatal behavioral changes in both humans and animals (for instance, summaries of human and rodent studies can be found in the review papers by Kingston et al., 2012 and Weinstock, 2008). It is not possible to review all of these findings, and also not the scope of this paper. Instead, here we summarize some of major findings on prenatal stress-induced behavioral alterations and discuss them in the context of environmental adaptation.

Both retrospective and prospective studies have been conducted to examine the relationship between prenatal stress/anxiety and offspring behaviors in human subjects. These studies found that prenatal stress/anxiety causes increased rate of low birth weight and preterm deliveries (Wadhwa et al., 1993), and augmented stress responses in offspring (Vrekoussis et al., 2010; Austin and Leader, 2000; Knackstedt et al., 2005; Phillips and Jones, 2006).

Whether a single, severe stress exposure during pregnancy may impact offspring behavior was investigated in mothers exposed to disasters. In the study with mothers who were stressed by Chernobyl exposure, offspring born from such stressed mothers were found to show slower motor and mental development as infants (Huizink et al., 2007). Children born from mothers exposed to Canadian ice storm exhibit altered pattern of play, lower general IQ, and language abilities than control groups, although whether these children have deficits in specific domain of cognitive functions other than language has remained unclear (Laplante et al., 2008). 
The study with mothers exposed to World Trade Center attack during pregnancy has reported that among these mothers, those who had subsequently developed post-traumatic stress disorder (PTSD) was found to exhibit lower baseline stress hormone level than others who did not develop PTSD (Yehuda and Bierer, 2008). Offspring born from such mothers who had developed PTSD have lower cortisol level and are more likely to develop PTSD than offspring born from the mothers without PTSD (Yehuda and Bierer, 2008).

Other studies examined the effects of prenatal stress with milder, but more prolonged exposure. Convergent evidence from various studies (for examples, O'Connor et al., 2002; Niederhofer, 2004; Rieger et al., 2004; Huizink et al., 2007) suggests that maternal anxiety/stress level during pregnancy is correlated with emotionality in offspring. Thus, offspring born from mothers with high anxiety/stress during pregnancy exhibit heightened anxiety and greater negative emotional behaviors. In contrast, whether maternal stress/anxiety during pregnancy affects cognitive function in human offspring has essentially remained unclear. For instance, maternal stress/anxiety during pregnancy has been also shown to increase intra-individual variability in performance of the reaction-time task in boys, but not girls (Loomans et al., 2011). This finding, however, does not necessarily mean that these offspring have cognitive impairments. Bergman and colleagues have reported that offspring born from mothers with higher stress hormone level during pregnancy exhibit greater fearfulness and slower cognitive development than offspring without prenatal stress. Moreover, these changes are more prominent in offspring born from stressed mothers experience insecure infant-mother attachment (Bergman et al., 2008). Niederhofer and colleagues have examined motor responses to vibroacoustic stimuli in the third trimester fetuses (Niederhofer, 2004). They found that the responses were attenuated in fetuses of mothers exposed to stress. Although they have 
suggested based on this finding that such attenuated responses to stimuli may be associated with learning impairments, this is apparently over-interpretation of the results.

Based on these studies, one seemingly convergent conclusion is, unlike animal studies discussed in the next section, the effects of prenatal stress on any specific domain of cognitive function in human offspring are not clear, whereas prenatal stress-induced alterations on emotionality are documented in some extent. Thus, a caution has to be given not to overtly apply findings of prenatal stress effects on cognitive impairments made in animals into human cases.

\subsection{Effects of prenatal stress in rodents and non-human primates}

A majority of animal studies investigating prenatal stress effects is conducted in rodents (mostly in rats), and less extent in non-human primates (mostly in rhesus macaques). Although in human studies, increased rate of lower birth weight and preterm deliveries are relatively consistently observed, these are controversial in rodents. Although one study has reported that prenatal stress results in smaller size of newborn pups (Drago et al., 1999), others were unable to find smaller pups (Guo et al., 1993; D'Mello and Liu, 2006) and altered duration of gestation (D'Mello and Liu, 2006), suggesting that general effects of stress on pregnancy may slightly differ between human subjects and rodents. However, similar to human offspring born from stressed mothers, stress response in rodent (Weinstock et al., 1992; Vallee et al., 1999; Koenig et al., 2005; Mastorci et al., 2009) and primate (Clarke et al., 1994) offspring exposed to prenatal stress seem more robust (i.e. prolonged stress hormone release) than that in animals without prenatal stress. 
An assortment of behavioral alterations, some of which are relatively consistently reported and others are controversial, has been reported to be caused by prenatal stress in rodents and non-human primates. These prenatal stress-induced behavioral alterations include deficits in cognitive function such as spatial learning (Vallee et al., 1999) and working memory (Vallee et al., 1999), affective function such as heightened anxiety (Vallee et al., 1997), fear-related behavior (Lehmann et al., 2000; Griffin et al., 2003), and abnormal social behaviors (Clarke and Schneider, 1993; Lee et al., 2007), and auditory sensory gating (Hunter et al., 2012; Koenig et al., 2005).

\subsection{Is spatial learning deficit adaptive behavioral change?}

Whether the behavioral alterations mentioned above are adaptation to cope with expected postnatal stressful condition is not apparent. Moreover, most of these altered behavioral phenotypes are clearly disadvantages in the non-stressful environmental condition. However, a cautious consideration on the relationship between stressor types and induced alterations may be able to provide a novel insight that indicates a possibility of adaptation, rather than deficit, of brain function to cope with an expected postnatal stress condition. In this context, it is interesting to note that majority of rodent studies examining prenatal stress effects have utilized restraint stress procedure.

Spatial learning and memory in rodents born from dams exposed to stress during gestation has been extensively investigated. In almost all studies utilizing restraint stress procedure, spatial memory has been reported to be impaired in offspring born from mothers exposed to prolonged, repeated restraint stress [for examples (Bustamante et al., 2010; Lui et al., 2011; Szuran et al., 1994; Vallee et al., 1999; Lemaire et al., 2000; Son et al., 2006; 
Hosseini-Sharifabad and Hadinedoushan, 2007; Yaka et al., 2007)], whereas there are also several studies showing enhancement of spatial memory with prenatal restraint stress (Fujioka et al., 2001; Cannizzaro et al., 2006), in which, however, restraint stress given to dams was milder (e.g. only single exposure) than the more commonly used procedure. Strikingly, spatial memory appears to be relatively intact or even enhanced with repeated exposure to stressors other than restraint such as exposure to stressful sensory stimuli (Kapoor et al., 2009), unfamiliar social group (Aleksandrov et al., 2001), and psychological stress by observation of other rodents being electrically shocked (Abe et al., 2007). Moreover, prenatal administration of glucocorticoids (Salomon et al., 2011) or dexamethasone (Brabham et al., 2000), does not affect spatial memory in offspring. These studies collectively indicate that spatial memory deficits may not be in fact "deficit” but rather "adaptation”. Indeed, the most characteristic feature of restraint stress is rigorous limitation of spatial information processing while pregnant rodents are exposed to stress. If restraint stress given to dams is prolonged and repeated (i.e. it is inescapable from stress by moving to other place), and this is the stress condition that offspring expects to encounter postnatally, spatial learning ability may be less important as it is inescapable from stress by moving to other places, and attenuated spatial learning ability may actually enable to better cope with anxiety/stress response associated with place-specific stress encountering. On the other hand, when stress is milder and brief (i.e. the condition that stress can be avoided by moving to another place), the most important action is to escape from and not to return to the place where stress is provoked. Thus, enhanced spatial learning may increase a chance to escape from danger or stress-provoking place. Adaptation, but not deficit, of spatial learning caused by prenatal restraint stress may be further supported by sexually dimorphic effects of prenatal stress. Although spatial memory is impaired in male offspring with severe 
prenatal restraint stress, it is conversely enhanced in female offspring (Bowman, 2005; Zuena et al., 2008). If altered spatial learning with prenatal restraint stress is a deficit, the reason of sexual dichotomy of prenatal stress-induced alterations on spatial learning is less clear. Indeed, enhancement of spatial memory may yield advantages to female animals, since information of a particular location is critical to them for assurance of resources (i.e. foods and shelters) for perseveration of the species even in the severe stress condition (New et al., 2007).

\subsection{Gender-associated behavioral changes as adaptation to social stress}

A further support that behavioral changes caused by prenatal stress may be adaptation to postnatal stress condition comes from a series of studies by Kaiser and colleagues investigating the effects of prenatal social stress in guinea pigs. In their studies, dams were exposed to social stress by placing them in unfamiliar groups of animals. Female offspring born from socially stressed dams exhibit a trait of masculinization such as high level of male-typical courtship behavior, increased testosterone level, and male-like (increased) androgen receptor distribution in the limbic system (Kaiser et al., 2003b). In contrast, male offspring born from socially stressed dams exhibit a trait of infantalizaiton/demasculinization such as less sexually-motivated courtship behavior, delayed maturation of the male hormonal system, infant-typical behavior such as resting with body contact on other animals, and down-regulation of androgen receptor expression in the limbic system (Kaiser et al., 2003a). Based on these observations, they have proposed that these gender-related changes in offspring caused by prenatal social stress may be adaptation to cope with a socially stressful (crowding) environment expected to encounter after birth (Kaiser and Sachser, 2009). Thus, masculinization may enable females to facilitate the attainment of dominant social class that may benefit securing of foods and shelters in the 
crowding environment. In contrast, infantilization/demasculinization may enable males to avoid agonistic encounters at early age and thereby increase a chance of later siring in the group and reproduction.

\subsection{Cognitive impairments with prenatal variable unpredictable stress}

The studies by Koenig and colleagues have utilized variable unpredictable stress to examine the effects of prenatal stress on offspring behaviors (Markham et al., 2010; Koenig et al., 2005). Variable unpredictable stress procedure employs exposure to different types of stressors over gestation. Interestingly, these studies found a wide range of behavioral alterations from sensory gating deficit to working and long-term memories, which are not to be reported in other studies with repeated exposure to a single modality of stress. There must be reasons that such various behavioral alterations are produced with exposure to variable prenatal stressors, and it may be adaptation to cope with expected postnatal stress condition, but such stress is originated in variable sources. For instance, decreased social interaction and working memory impairments caused by prenatal stress appear to cause only disadvantages, and there is no apparent benefit at all. Nevertheless, for instance, a stressful environment expects less survivors and poor social organization than the non-stressful condition. In such condition, prenatal stress-induced decrease of social interaction may increase a chance of survival with less social-dependence and greater resistance against social isolation. In a life-threatening severe environment, analytical and critical thinking that depends on working memory may not be much useful, whereas almost automatic stimulus-response (escape) behavior may even increase a chance of survival.

\section{Biological mechanisms of maternal-to-fetal communication of stress}


Studies often report variable, and sometimes even opposite, effects of prenatal stress. It is believed that such differential stress effects may be associated with timing, severity, and duration of stress exposure, as well as stressor types. In prenatal stress effects, timing of stress exposure appears to be the greatest concern, as depending on when maternal stress is given during pregnancy, stress may affect different developmental stages in fetuses, leading of distinct outcomes. However, timing of stress exposure alone apparently does not explain all differences of prenatal stress-induced alterations, as the results of studies with prenatal stress given at the identical developmental stage are still mixed (Charil et al., 2010; Grizenko et al., 2008; Kinney et al., 2008; Weinstock, 2008).

In contrast, from both human and animal studies described above, it appears that behavioral changes caused by prenatal stress are significantly associated with stressor types. This challenges the generally accepted belief that prenatal stress-induced alterations in fetuses are achieved by maternal-to-fetal transfer of stress hormones (Charil et al., 2010; Avishai-Eliner et al., 2002). Indeed, some alterations in offspring born form dams exposed to stress may be associated with maternal-to-fetal transfer of stress hormones. Such alterations would be mutually produced by exposure to stress regardless of stressor types. In contrast, behavioral changes associated with a specific stress modality may involve molecules other than stress hormones. For instance, this is clearly supported by the studies showing that, unlike restraint stress, administration of stress hormones, corticosterone (Salomon et al., 2011) or dexamethasone (Brabham et al., 2000), to dams does not impair spatial memory in offspring.

One potential candidate of such molecules may be microRNA (miRNA). miRNA is an endogenous, short, double strand, RNA (Carthew and Sontheimer, 2009). miRNA has been shown to be an important regulator of brain development (Sayed and Abdellatif, 2011; Coolen 
and Bally-Cuif, 2009). miRNA can circulate the body with exosome encapsulation, and plays important role on cell-cell communications (Valadi et al., 2007; Mitchell et al., 2008). Moreover, specific classes of miRNA are dynamically expressed in the placenta throughout pregnancy (Chiu and Lo, 2010; Miura et al., 2010; Chim et al., 2008), and their pregnancy-related expression are altered by maternal conditions such as smoking (Maccani et al., 2010) and hypoxia (Mouillet et al., 2010). Indeed, placenta-derived exosomes have been implicated to influence fetal growth (Mincheva-Nilsson and Baranov, 2010). Collectively, maternal-to-fetal transfer of miRNA may be involved in maternal-to-fetal communication and produce environmentally-specific alterations on fetal development.

\section{Adaptation to other environmental factors}

The effects of prenatal exposure to various environmental factors other than stress on offspring health outcomes have been also examined. These include prenatal exposure to immunotoxicants including viruses and allergens. Consistent findings are potentiated responses to postnatal exposure to the stimuli that are exposed in utero. Thus, organisms exposed to immunotoxicants in utero exhibit heightened immune and inflammatory activation, often expressed as autoimmune diseases (Holladay, 1999). Children born from mothers exposed to allergens during pregnancy exhibit greater allergic responses, but also improved respiratory function (Woodcock et al., 2004). Potentiated responses to environmental stimuli could add a significant advantage in organisms for survival in the adverse environmental conditions by enabling early detection of threats, and escape from them. Moreover, prenatal exposure to environmental stimuli such as viruses, famine, and stress produces various behavioral changes in offspring, some of which are, however, mutually observed regardless of exposure to completely 
distinct environmental stimuli. These mutual behavioral changes caused by distinct prenatal environmental factors may therefore be considered as adaptation to generalized adversities or threats independent of a modality of environmental conditions.

Adaptation to environmental stimuli may also happen at the perinatal and neonatal periods as well as even in adulthood. Obstetric complications, especially the case that involves hypoxia, have been shown to induce behavioral changes in offspring (Boksa, 2004). Such hypoxia-induced alterations may be similar to prenatal exposure to high altitude that could alter uterine artery blood flow and arterial $\mathrm{PCO}_{2} / \mathrm{O}_{2}$ saturation (Julian et al., 2007), but hypoxia in obstetric complication is more brief and severe than the high altitude condition. Studies of cerebral ischemia in adult brains suggest that glial cells play a major role on protective (adaptive) response to ischemia (Nedergaard and Dirnagl, 2005). Thus, if obstetric complication may induce adaptive changes, it may alter glial function, which in turn alters behaviors of offspring. In this context, it is interesting to note that obstetric complication is a robust risk factor of schizophrenia [e.g. 10-fold greater likelihood of developing schizophrenia in offspring (Verdoux et al., 1997)], and altered glial function has been implicated in the pathology of schizophrenia (Mitterauer, 2011; Moises and Gottesman, 2004; Rothermundt et al., 2007).

\section{Prenatal environmental adaptation hypothesis}

Collectively from the studies described above, it appears that behavioral alterations observed in offspring born from mothers exposed to a particular environmental condition follow a specific modality of that environmental factor. Thus, for instance, if prenatal stress-induced alterations are adaptation (i.e. preparing to anticipated postnatal stressful life) rather than deficits, offspring born from mothers exposed to stress may be benefited with the alterations in the postnatal 
stressful condition, whereas these individuals may have disadvantages with the alterations in the non-stressful environmental condition. In contrast, the phenotypes that develop during environmental conditions without stress could be also adaptive. This leads to a hypothesis that prenatal environmental conditions influence the development of behavioral phenotypes in offspring that can represent adaptations that match with expected postnatal environmental conditions. Indeed, such a hypothesis is not a new, but has been already proposed by others (Kaiser and Sachser, 2009).

\section{Prenatal and postnatal stress interaction}

The hypothesis implicates the importance of longitudinal investigation of stress effects, which has been barely conducted previously. Extensive studies have been conducted to examine the effects of prenatal or postnatal stress alone. In contrast, there are only few studies examining stress effects with multiple times of exposure along different ages. Indeed, stress exposure is not a single life event, but more likely to be multiple times throughout the life. In particular, whether alterations caused by stress are deficits or adaptation must be withdrawn only by examining how alterations produced at the first time of stress exposure impact on responses to subsequent stress exposure.

Several studies have investigated interaction between the effects of prenatal stress and postnatal stress; however, almost all of them are limited during the neonatal period. A line of evidence has argued that expression of at least some aspects of behavioral alterations caused by prenatal stress requires a neonatal stress condition such as decreased maternal care. This is based on the finding that dams exposed to stress provide less maternal care to pups than non-stressed mothers (Champagne and Meaney, 2006). Moreover, cross-fostering of pups born 
from stressed dams to non-stressed dams diminishes prenatal stress-induced behavioral alterations (Del Cerro et al., 2010; Maccari et al., 1995; Barbazanges et al., 1996; Burton et al., 2006). It has been also shown that prenatal stress effects are reversed by neonatal handling (Wakshlak and Weinstock, 1990). These studies suggest that neonatal period may be a window to match with prenatal and postnatal environmental condition, with early postnatal stress such as insufficient mother-infant attachment augmenting, whereas better than the expected environmental condition such as sufficient mother-infant attachment reversing, the effects of prenatal stress.

Modulation of prenatal stress effects by postnatal environmental condition also supports that alterations caused by prenatal stress are adaptation. If prenatal stress-induced alterations are "deficits", ceiling effects are expected (e.g. maternal deprivation has smaller effects on prenatal stress-induced alterations). Moreover, it appears that potentiation by maternal deprivation, and reversal by increased maternal care, of prenatal stress effects may be best interpreted as the process that maternal deprivation (i.e. matching with prenatal and postnatal conditions as stressful) ensures the necessity of behavioral changes caused by prenatal stress, whereas prenatal stress-induced alterations are reversed because the postnatal environmental condition does not meet with the prenatal stressful condition. Indeed, in this context, that stressed mothers provide less maternal care to pups is more reasonably understandable.

\section{Biological substrate of prenatal environmental adaptation}

Development of synaptic connections in the cortex and limbic structures starts during the prenatal period. In human prefrontal cortex (PFC), synaptogenesis and synaptic proliferation continues up around 5 6 year olds, and subsequently subjected for synaptic pruning throughout 
adolescence for fine tuning of the network (Huttenlocher, 1984; Rakic et al., 1986). Thus, development and maturation of PFC synaptic network continues from the prenatal period to early adulthood, and thereby, dynamic synaptic changes can be influenced by both prenatal and postnatal environmental conditions. A similar pattern of over-production of synaptic connections followed by pruning is also observed in limbic structures such as the hippocampus of rodents (Afadlal et al., 2010), although this appears to be less clear in the human hippocampus (Eastwood et al., 2006).

Prenatal stress (Afadlal et al., 2010; Mychasiuk et al., 2012; Murmu et al., 2006) and malnutrition (Diaz-Cintra et al., 1994) have been shown to decrease synaptogenesis in the cortex/hippocampus, whereas prenatal viral infection and associated immune activation appears to produce more complex patterns of alterations through development and maturation of the brain (Soumiya et al., 2011; Baharnoori et al., 2009). Such alterations are generally accepted as neurodevelopmental deficits that cause brain function. However, if fetal alterations caused by prenatal environmental exposure is adaptation, decreased synaptogenesis should be also interpreted as adaptation, which (i) may be a form of accelerated brain maturation (e.g. decreased synaptic connections may be considered a similar state to adult brain after pruning, or the amount of synaptogenesis and pruning may be smaller, and thereby maturation is achieved quicker), advantaging the organisms to survive the severe environmental condition during early postnatal period, and/or (ii) may provide protective effects on behavioral and brain changes caused by postnatal environmental threats. There has been no evidence so far that whether and how alterations of PFC synaptic development and maturation caused by prenatal and postnatal stress may interact. However, the ingenious study by Lueba and Rabinowicz indirectly supports these possibilities (Leuba and Rabinowicz, 1979). They found that postnatal under-nutrition caused 
dendritic atrophy and decreased number of dendritic spines in the mouse cortex, which persisted into adulthood. However, postnatal under-nutrition was combined with maternal under-nutrition during pregnancy, cortical cell dendritic alterations were, although they were still present during the juvenile period, not observed when offspring reached adulthood. Further investigation on how prenatal and postnatal environmental interaction shapes cortical and limbic synaptic network would be a promising venue.

\section{Psychiatric disorders as environmental adaptation}

One dilemma, if prenatal/neonatal changes are adaptation process to environments, is since prenatal exposure to environmental insults such as exposure to stress, famine, and viral infection are suggested to increase the risks of psychiatric disorders such as schizophrenia, ADHD, and autism, these psychiatric disorders associated with prenatal environmental insults and involving PFC dysfunction may consequently be considered as environmental adaptation, rather than deficits, of the brain. This deviant idea from the generally accepted belief of psychiatric disorders as brain dysfunction may be reconciled by consideration of the evolutionary biology/medicine.

Evolutionary biology/medicine suggests that psychiatric disorders may in fact arise by environmental adaption through evolution to bring benefits on survival and fecundity of organisms. Thus, although the symptoms of several psychiatric conditions are incompatible with the modern society, they may benefit in certain specific environmental conditions. It is also possible that psychiatric disorders may still be disadvantageous if it is a by-product of evolution (i.e. an extreme variant of adaptive behavior). 
For instance, Jensen and colleagues have suggested that the core symptoms of ADHD such as hyperactivity, impulsivity, and attention deficit, although these symptoms are clearly problems in the modern society, bring significant benefits on survival of organisms in a specific environment where dangers and threats are approaching (Jensen et al., 1997). Thus, hyperactivity enables greater exploration of surrounding environments for threats and opportunities. Impulsivity enables quick response to environmental cues while not considering alternative responses to the cues to escape form dangers and threats. Attention deficit observed in ADHD subjects is inability to sustain attention to a particular object. However, this in turn results in shifting of attention and scanning from one object to another rapidly to monitor dangers and threats.

Andrews and Thomson have proposed that the symptoms of major depressive disorder MDD are beneficial behavioral changes (Andrews and Thomson, 2009). Patients with MDD are known to exhibit highly persistent and analytical thinking on a particular issue (i.e. rumination). Moreover, primary MDD symptoms are social withdrawal/isolation and loss of pleasure on other activities. These behavioral phenotypes, however, enable to prevent interruption of thinking, and therefore, MDD patients can concentrate on overcoming the problem that gives stress and causes MDD. They further suggests that, since serotonin (5HT) 1A receptor is involved in the pathologies of MDD, 99\% identical composition of the functional part of $5 \mathrm{HT}_{1 \mathrm{~A}}$ receptor between rodents and human subjects supports emergence of MDD as positive evolutionary selection. However, it is important to note that $5 \mathrm{HT}_{1 \mathrm{~A}}$ receptor also plays an important role in cognitive processing (Beste et al., 2010; Winstanley et al., 2003; Meneses and Perez-Garcia, 2007), and therefore, the argument that conservation of $5 \mathrm{HT}_{1 \mathrm{~A}}$ receptor may explain the positive evolutionary selection of MDD is overstretching. 
From the evolutionary perspective, it is also interesting to note some similarities between MDD and hibernation. First, occurrence of MDD is higher during the winter term with shorter day light (Blehar and Rosenthal, 1989). In addition, one of the major symptoms of MDD is sleep problems (Thase, 1998). During hibernation, circadian rhythm is suppressed (Hut et al., 2002). Disruption of circadian rhythm is also observed in MDD (Monteleone et al., 2011). Hibernation is the mechanism of energy conservation with lower metabolic rate. In MDD patients, the metabolic syndromes such as type II diabetes are frequent co-morbid disorders (Musselman et al., 2003). Finally, MDD and hibernation appear to have the common biological mechanisms that involve $5 \mathrm{HT}$ transmission and $5 \mathrm{HT}_{1 \mathrm{~A}}$ stimulation in the hippocampus (Albert and Lemonde, 2004; Horrigan et al., 1997; Naumenko et al., 2008) as well neuronal activity in the epithalamic nucleus, habenula (Li et al., 2011; Yu et al., 2002). Although there are indeed clear differences between MDD and hibernation, it may not be too much anomalous to think based on the similarities that MDD may be a trace of hibernation that has remained through evolution in human subjects as the energy conservation mechanisms with the MDD symptoms such as withdrawal from the society and decreased interest to various activities. Indeed, hibernation is a strategy that some animals take for energy conservation during the winter time while not many foods are available. In this regard, MDD may be also considered as an energy conservation strategy, which makes MDD patients await without loss of much energy until that the problems that the subjects are facing with pass away (Schmale and Engel, 1975).

\section{Psychiatric disorders involving neurodevelopmental changes}

It is interesting to note that psychiatric disorders appear to be strongly associated in neuorodevelopmental changes. Even in psychiatric disorders such as MDD, anorexia nervosa, 
and schizophrenia, in which symptoms typically emerge in adolescence or young adulthood, epidemiological studies have shown the increased risks of these disorders in offspring with low birth weight (Abel et al., 2010; Cnattingius et al., 1999; Mick et al., 2002; Costello et al., 2007), obstetric complication [anorexia nervosa (Favaro et al., 2006) and schizophrenia (Geddes and Lawrie, 1995), but not for MDD (Bain et al., 2000; Preti et al., 2000)], and exposure to prenatal environmental factors such as stress (Ronald et al., 2011; van Os and Selten, 1998; Rodriguez and Bohlin, 2005; Khashan et al., 2008; Malaspina et al., 2008), famine (Brown et al., 1995b; Brown et al., 2000; Susser et al., 1996), and virus infection (Favaro et al., 2011; Mednick et al., 1988; Brown et al., 1995a; Brown, 2006; Machon et al., 1997). Thus, prenatal period may be the critical time window for environmental adaptation incorporated into evolution, which in turn may originate psychiatric conditions that bring benefits for survival of organisms in severe environmental conditions.

\section{PFC dysfunction in psychiatric disorders}

The PFC is thought to be the brain region that is evolutionarily the latest and most complex area (Smaers et al., 2011; Teffer and Semendeferi, 2012). The PFC plays a central role on executive function, along with integration of information from other parts of the brain such as limbic structures, basal ganglia, cerebellum, and other corticies (Fuster, 2001; Wood and Grafman, 2003). Allometric analysis of brain structures suggest that the human PFC is approximately twice larger, and almost six times larger than predicted based on overall brain and body sizes, respectively, of other non-human primates (Deacon, 1988; Stephan et al. 1988; McBride et al., 1999; Rilling, 2006; Semendeferi et al., 2002). 
In particular, dysfunction of the PFC has been implicated in almost all psychiatric disorders (Pietrini et al., 2011; Weinberger et al., 1994; Seidman et al., 2005; Drevets, 2000). It is surprising that just one brain region is involved in various distinct psychiatric symptoms. However, this could be explained by that the PFC has extensive connections with many other parts of the brain, such that deficits in other brain structures are reflected in activity of the PFC, even if there is no deficit in the PFC itself.

Alterations in developmental trajectory of PFC synaptic network have been suggested in the disorders such as schizophrenia (Eastwood and Harrison, 2005) and ADHD (Shaw et al., 2007). Indeed, the PFC is highly plastic brain region and altered by various prenatal and postnatal environmental conditions including stress (Lyons et al., 2002; Murmu et al., 2006). Moreover, development of PFC synaptic network starts from the prenatal period, continues to develop even after birth, and does not mature up until adulthood (Petanjek et al., 2011). Therefore, the PFC synaptic network may be particularly sensitive for both prenatal and postnatal environmental conditions.

Collectively, PFC synaptic network appears a crucial neural substrate through which prenatal and postnatal environmental adaptation can take place.

\section{Psychiatric disorders in evolution}

The Darwinian evolutionary theory, which has been widely accepted, argues that the primary driving force of evolution is stochastic, random genetic drifts, which create various phenotypes. These variable phenotypes are subjected for natural selection, and organisms with the phenotype that is most suitable to the specific environment have been inherited into descendents. Nevertheless, such stochastic genetic drifts appear to be unfavorable explanation for emergence 
of psychiatric disorders in evolution. For instance, malaria infection and sickle-cell trait are the well-documented example of evolution (Kwiatkowski, 2005). Malaria infection is a common fatal disorder in Africa, and sickle-cell trait is thought to emerge in African people to reduce the risk of death by Malaria infection. It has been shown that approximately $10 \%$ of African people possesses sickle-cell trait. In contrast, however, only about $4 \%$ in African-Americans, who are five generation descendants of African people immigrated to US, exhibit such a trait (Hassell, 2010). Indeed, Malaria is an uncommon disease, and therefore, sickle-cell is unnecessary trait for people living in US, suggesting that evolution of the sickle-cell trait was subjected for natural selection. On the other hand, evolution of psychiatric disorders appears to be challenged by the fact of high constant prevalence in population all over the world throughout the history (World Health Organization, 2000). If psychiatric disorders are evolved by stochastic genetic drifts with subsequent natural selection, it is likely that prevalence of disorders decreases because of mismatch with the modern human society.

\section{Epigenetic-based mechanisms of transgenerational inheritance of behaviors}

The French naturalist, Lamarck proposed the mechanism of evolution that was different from the Darwinian theory. In Lamarckian inheritance, the primary driving force of evolution is adaptation of organisms to their specific environments in the life, and acquired phenotypes are inherited into descendants. This theory was once doomed as incorrect, and only few people have supported it. However, emerging evidence has proved that Lamarckian-like inheritance does occur.

In human studies, it has been shown that offspring of mothers who exposed to Dutch famine in 1943-1947 in utero exhibit increased neonatal adiposity and poor health outcomes such 
as autoimmune, respiratory, infectious, and dermatological problems, later in life (Painter et al., 2008). Similarly, offspring of mothers who exposed to diethylstilbestrol in utero have higher rate of hypospadias (Brouwers et al., 2006), suggesting that maternal lineage of transmission of changes caused by prenatal environmental insults across generation.

Animal studies further supports transgenerational inheritance of behavioral phenotypes caused by prenatal exposure to environmental stimuli. Such transgenerational transmission was first reported by Wehmer and colleagues (Wehmer et al., 1970). They found that progenies $\left(\mathrm{F}_{2}\right)$ of female rats $\left(\mathrm{F}_{0}\right)$ subjected for foot shock stress before mating and during pregnancy exhibited hyperactivity compared to $F_{2}$ descendants of non-stressed $F_{0}$ mothers. More recently, Drake and colleagues examined the effects of maternal administration of stress hormone during pregnancy (Drake et al., 2005). Male and female progenies $\left(F_{2}, F_{3}\right)$ of fathers and mothers $\left(F_{1}\right)$ exposed to stress hormone in utero were found to be smaller in birth weight and develop glucose tolerance with increased phosphoenolpyruvate carboxykinase activity. Similarly, the study by Morgan and colleagues has shown that male offspring $\left(F_{2}\right)$ of fathers $\left(F_{1}\right)$ exposed to stress in utero exhibit more female-like gene expression pattern than that in male progenies of non-prenatally stressed fathers, suggesting paternal lineage of transgenerational transmission of alterations (Morgan and Bale, 2011).

Studies have also shown transgenerational inheritance of phenotypes in response to prenatal exposure to environmental stimuli other than stress. In one study, pregnant rats $\left(\mathrm{F}_{0}\right)$ were exposed to protein restriction diet (Bertram et al., 2008). Female offspring $\left(\mathrm{F}_{1}\right)$ born from such dams with protein restriction were grown up with either protein restriction or adequate diet. Insulin resistance was observed in male offspring $\left(F_{2}\right)$ of $F_{1}$ females grown with protein restriction, whereas female offspring $\left(F_{2}\right)$ of $F_{1}$ females grown with adequate diet exhibited 
insulin resistance. Zambrano and colleagues investigated maternal nutrient restriction diet during pregnancy in guinea pigs (Zambrano et al., 2005). Female offspring $\left(\mathrm{F}_{1}\right)$ were grown up in the adequate nutrient and mated with non-nutrition restricted males to produce progenies $\left(\mathrm{F}_{2}\right)$. $F_{1}$ and $F_{2}$ male offspring exhibited altered cardiovascular function and elevated stress response compared to descendants of adequate nutrition across generation.

Transgenerational transmission of behavioral phenotypes appears not constricted to those associated with prenatal environmental conditions, but neonatal or even adult environments. Thus, descendants of fathers exposed to maternal deprivation during the neonatal period have been shown to exhibit behavioral phenotypes associated with depression (Franklin et al., 2010). Moreover, in these descendants, DNA methylation on corticotrophin-releasing factor receptor 2 and cannabinoid receptor- 1 are inherited from the fathers exposed to maternal deprivation. Another study examined the effects of neonatal exposure to lipopolysaccharide (LPS), which has been shown to induce anxiety-like behavior, in male and female rats. Offspring of female rats who received LPS was found to exhibit heightened anxiety-like behavior and potentiated stress response, whereas offspring of male rats with neonatal LPS exhibited anxiety-like phenotype, but no alteration on stress response (Walker et al., 2012). Whether behavioral changes caused by chronic stress given in adult rodents were also transmitted into offspring was examined in the study by Dietz and colleagues. They found that male offspring of stressed fathers, but not mothers, exhibited increased stress hormone level, as well as increased anxiety and decreased reward seeking behavior (Dietz et al., 2011). This finding in rodents is, however, slightly different from the human case (Yehuda and Bierer, 2008), which reports that offspring of Holocaust survivors with PTSD demonstrate lower stress hormone level than offspring of 
Holocaust survivors without PTSD, this is inherited from female survivors rather than male survivors.

Epigenetic mechanisms play a central role of Lamarckian-like transgenerational inheritance of behavioral phenotypes. Epigenetic regulation of gene expression usually involves chromatin modification such as histone acetylation and DNA methylation (Borrelli et al., 2008). Although inheritance of typical chromatin modification across generation has been confirmed in some studies (Franklin et al., 2010), it appears that miRNA transmitted across generation through gametes also plays significant role on this type of inheritance (Daxinger and Whitelaw, 2012; Rechavi et al., 2011; Rassoulzadegan et al., 2006).

\section{Transgenerational epigenetic inheritance as evolutionary biological bases of psychiatric disorders}

Collectively from the studies described above, we propose a hypothesis that rapid, epigenetic-based mechanisms of environmental adaptation, especially during the prenatal period, may be the primary driving force for generation of psychiatric disorders in evolution. Thus, psychiatric disorders may be better understood under the concept of environmental adaptation of fetal development with epigenetic reprogramming.

This hypothesis has both pros and cons. Pros of the hypothesis are non-Mendelian pattern of expression of transmitted genes (Morgan et al., 1999; Sutherland et al., 2000), which is consistent with the observed non-Mendelian inheritance of psychiatric disorders. Moreover, epigenetic transgenerational inheritance also has an explanatory value on parental imprinting. It is often suggested that psychiatric disorders such as schizophrenia and autism are paternal or maternal origin (Shelton et al., 2010; Brown et al., 2002; Crespi and Badcock, 2008). Cons of 
the hypothesis include unknown mechanisms transferring epigenetic changes into equivalent DNA changes. However, the mechanisms such as that proposed by Baldwin (Baldwin and Mark, 1896), and genetic assimilation that Waddington has experimentally demonstrated for stimulus-dependent (i.e. heat shock-induced) to stimulus-independent inheritance of crossveinless in drosophila (Waddington, 1953) would enable transfer of epigenetic changes into DNA changes. In addition, investigation of epigenetic inheritance and its mechanisms has been mostly conducted in rodents and lower vertebrates/invertebrates. It still remains to be examined that similar epigenetic-based inheritance mechanisms may be observed in primates. It is of particular interest to investigate whether any commonality may be found on epigenetic patterns of transgenes between psychiatric patients and subjects exposed to adverse environmental conditions.

\section{Conclusion}

In this article, we have proposed the two hypotheses. First, neurodevelopmental changes particularly occurring in the PFC of fetuses with exposure a specific prenatal environmental condition may be adaptation to cope with the environment that is anticipated in postnatal life. Extensive studies have unveiled the effects of prenatal environmental effects on offspring behaviors and brain function. These studies, however, took environmental exposure as a single life event, and did not consider the longitudinal aspect of environmental exposure. Taking this into account, it is important to consider how alterations caused by the first exposure of a specific environmental condition interact with re-exposure to the identical or even different environmental condition to fully understand the significance of the environment-associated alterations occurring in organisms. 
The second hypothesis is that psychiatric disorders may be emerged through evolution as environmental adaptation with epigenetic inheritance. In particular, presence of the mechanism that can auspiciously transmit a defect across generation is unfavorable. Thus, epigenetic-based transgenerational inheritance of behavioral phenotypes prefers the explanation that such inherited alterations may not be deficits, but rather adaptation, to cope with environmental threats. Investigation and understanding of alterations in the context of such views will bring a novel insight on our understanding of psychiatric disorders. 


\section{Conflict of interest}

None

\section{Acknowledgements}

The authors are supported by Kyoto University.

\section{References}


Abe, H., Hidaka, N., Kawagoe, C., Odagiri, K., Watanabe, Y., Ikeda, T., Ishizuka, Y., Hashiguchi, H., Takeda, R., Nishimori, T., and Ishida, Y. (2007). Prenatal psychological stress causes higher emotionality, depression-like behavior, and elevated activity in the hypothalamo-pituitary-adrenal axis. Neurosci Res 59, 145-151.

Abel, K.M., Wicks, S., Susser, E.S., Dalman, C., Pedersen, M.G., Mortensen, P.B., and Webb, R.T. (2010). Birth weight, schizophrenia, and adult mental disorder: is risk confined to the smallest babies? Arch Gen Psychiatry 67, 923-930.

Afadlal, S., Polaboon, N., Surakul, P., Govitrapong, P., and Jutapakdeegul, N. (2010). Prenatal stress alters presynaptic marker proteins in the hippocampus of rat pups. Neurosci Lett 470, 24-27.

Albert, P.R., and Lemonde, S. (2004). 5-HT1A receptors, gene repression, and depression: guilt by association. Neuroscientist 10, 575-593.

Aleksandrov, A.A., Polyakova, O.N., and Batuev, A.S. (2001). The effects of prenatal stress on learning in rats in a Morris maze. Neurosci Behav Physiol 31, 71-74.

Andrews, P.W., and Thomson, J.A., Jr. (2009). The bright side of being blue: depression as an adaptation for analyzing complex problems. Psychol Rev 116, 620-654.

Austin, M.P., and Leader, L. (2000). Maternal stress and obstetric and infant outcomes: epidemiological findings and neuroendocrine mechanisms. Aust N Z J Obstet Gynaecol 40, 331-337.

Avishai-Eliner, S., Brunson, K.L., Sandman, C.A., and Baram, T.Z. (2002). Stressed-out, or in (utero)? Trends Neurosci 25, 518-524.

Baharnoori, M., Brake, W.G., and Srivastava, L.K. (2009). Prenatal immune challenge induces developmental changes in the morphology of pyramidal neurons of the prefrontal cortex and hippocampus in rats. Schizophr Res 107, 99-109.

Bain, M., Juszczak, E., Mcinneny, K., and Kendell, R.E. (2000). Obstetric complications and affective psychoses. Two case-control studies based on structured obstetric records. $\mathrm{Br} J$ Psychiatry 176, 523-526.

Baldwin, J.M. (1896). A new factor in evolution. Am Natur 30, 441-451.

Barbazanges, A., Vallee, M., Mayo, W., Day, J., Simon, H., Le Moal, M., and Maccari, S. (1996). Early and later adoptions have different long-term effects on male rat offspring. $J$ Neurosci 16, 7783-7790.

Barker, D.J. (1997). Maternal nutrition, fetal nutrition, and disease in later life. Nutrition 13, 807-813.

Bergman, K., Sarkar, P., Glover, V., and O'connor, T.G. (2008). Quality of child-parent attachment moderates the impact of antenatal stress on child fearfulness. J Child Psychol Psychiatry 49, 1089-1098.

Bertram, C., Khan, O., Ohri, S., Phillips, D.I., Matthews, S.G., and Hanson, M.A. (2008). Transgenerational effects of prenatal nutrient restriction on cardiovascular and hypothalamic-pituitary-adrenal function. J Physiol 586, 2217-2229.

Beste, C., Heil, M., Domschke, K., and Konrad, C. (2010). The relevance of the functional 5-HT1A receptor polymorphism for attention and working memory processes during mental rotation of characters. Neuropsychologia 48, 1248-1254.

Blehar, M.C., and Rosenthal, N.E. (1989). Seasonal affective disorders and phototherapy. Report of a National Institute of Mental Health-sponsored workshop. Arch Gen Psychiatry 46, 469-474. 
Boksa, P. (2004). Animal models of obstetric complications in relation to schizophrenia. Brain Res Brain Res Rev 45, 1-17.

Borrelli, E., Nestler, E.J., Allis, C.D., and Sassone-Corsi, P. (2008). Decoding the epigenetic language of neuronal plasticity. Neuron 60, 961-974.

Bowman, R.E. (2005). Stress-induced changes in spatial memory are sexually differentiated and vary across the lifespan. J Neuroendocrinol 17, 526-535.

Brabham, T., Phelka, A., Zimmer, C., Nash, A., Lopez, J.F., and Vazquez, D.M. (2000). Effects of prenatal dexamethasone on spatial learning and response to stress is influenced by maternal factors. Am J Physiol Regul Integr Comp Physiol 279, R1899-1909.

Brouwers, M.M., Feitz, W.F., Roelofs, L.A., Kiemeney, L.A., de Gier, R.P., and Roeleveld, N. (2006). Hypospadias: a transgenerational effect of diethylstilbestrol? Hum Reprod 21, 666-669.

Brown, A.S. (2006). Prenatal infection as a risk factor for schizophrenia. Schizophr Bull 32, 200-202.

Brown, A.S., Schaefer, C.A., Wyatt, R.J., Begg, M.D., Goetz, R., Bresnahan, M.A., Harkavy-Friedman, J., Gorman, J.M., Malaspina, D., and Susser, E.S. (2002). Paternal age and risk of schizophrenia in adult offspring. Am J Psychiatry 159, 1528-1533.

Brown, A.S., Susser, E.S., Lin, S.P., and Gorman, J.M. (1995a). Affective disorders in Holland after prenatal exposure to the 1957 A2 influenza epidemic. Biol Psychiatry 38, 270-273.

Brown, A.S., Susser, E.S., Lin, S.P., Neugebauer, R., and Gorman, J.M. (1995b). Increased risk of affective disorders in males after second trimester prenatal exposure to the Dutch hunger winter of 1944-45. Br J Psychiatry 166, 601-606.

Brown, A.S., van Os, J., Driessens, C., Hoek, H.W., and Susser, E.S. (2000). Further evidence of relation between prenatal famine and major affective disorder. Am J Psychiatry 157, 190-195.

Burton, C., Lovic, V., and Fleming, A.S. (2006). Early adversity alters attention and locomotion in adult Sprague-Dawley rats. Behav Neurosci 120, 665-675.

Bustamante, C., Bilbao, P., Contreras, W., Martinez, M., Mendoza, A., Reyes, A., and Pascual, R. (2010). Effects of prenatal stress and exercise on dentate granule cells maturation and spatial memory in adolescent mice. Int J Dev Neurosci 28, 605-609.

Cannizzaro, C., Plescia, F., Martire, M., Gagliano, M., Cannizzaro, G., Mantia, G., and Cannizzaro, E. (2006). Single, intense prenatal stress decreases emotionality and enhances learning performance in the adolescent rat offspring: interaction with a brief, daily maternal separation. Behav Brain Res 169, 128-136.

Carthew, R.W., and Sontheimer, E.J. (2009). Origins and Mechanisms of miRNAs and siRNAs. Cell 136, 642-655.

Champagne, F.A., and Meaney, M.J. (2006). Stress during gestation alters postpartum maternal care and the development of the offspring in a rodent model. Biol Psychiatry 59, 1227-1235.

Charil, A., Laplante, D.P., Vaillancourt, C., and King, S. (2010). Prenatal stress and brain development. Brain Res Rev 65, 56-79.

Chim, S.S., Shing, T.K., Hung, E.C., Leung, T.Y., Lau, T.K., Chiu, R.W., and Lo, Y.M. (2008). Detection and characterization of placental microRNAs in maternal plasma. Clin Chem 54, 482-490.

Chiu, R.W., and Lo, Y.M. (2010) Pregnancy-associated microRNAs in maternal plasma: a channel for fetal-maternal communication? Clin Chem 56, 1656-1657. 
Clarke, A.S., and Schneider, M.L. (1993). Prenatal stress has long-term effects on behavioral responses to stress in juvenile rhesus monkeys. Dev Psychobiol 26, 293-304.

Clarke, A.S., Wittwer, D.J., Abbott, D.H., and Schneider, M.L. (1994). Long-term effects of prenatal stress on HPA axis activity in juvenile rhesus monkeys. Dev Psychobiol 27, 257-269.

Cnattingius, S., Hultman, C.M., Dahl, M., and Sparen, P. (1999). Very preterm birth, birth trauma, and the risk of anorexia nervosa among girls. Arch Gen Psychiatry 56, 634-638.

Coolen, M., and Bally-Cuif, L. (2009). MicroRNAs in brain development and physiology. Curr Opin Neurobiol 19, 461-470.

Costello, E.J., Worthman, C., Erkanli, A., and Angold, A. (2007). Prediction from low birth weight to female adolescent depression: a test of competing hypotheses. Arch Gen Psychiatry 64, 338-344.

Crespi, B., and Badcock, C. (2008). Psychosis and autism as diametrical disorders of the social brain. Behav Brain Sci 31, 241-261; discussion 261-320.

D'Mello A, P., and Liu, Y. (2006). Effects of maternal immobilization stress on birth weight and glucose homeostasis in the offspring. Psychoneuroendocrinology 31, 395-406.

Daxinger, L., and Whitelaw, E. (2012). Understanding transgenerational epigenetic inheritance via the gametes in mammals. Nat Rev Genet 13, 153-162.

Deacon, T.W. (1988). Human brain evolution: II. Embryology and brain allometry. In: Jerison, H., Jerison, I., eds. Intelligence and Evolutionary Biology Berlin: Springer-Verlag. 383-415

Del Cerro, M.C., Perez-Laso, C., Ortega, E., Martin, J.L., Gomez, F., Perez-Izquierdo, M.A., and Segovia, S. (2010). Maternal care counteracts behavioral effects of prenatal environmental stress in female rats. Behav Brain Res 208, 593-602.

Diaz-Cintra, S., Garcia-Ruiz, M., Corkidi, G., and Cintra, L. (1994). Effects of prenatal malnutrition and postnatal nutritional rehabilitation on CA3 hippocampal pyramidal cells in rats of four ages. Brain Res 662, 117-126.

Dietz, D.M., Laplant, Q., Watts, E.L., Hodes, G.E., Russo, S.J., Feng, J., Oosting, R.S., Vialou, V., and Nestler, E.J. (2011). Paternal transmission of stress-induced pathologies. Biol Psychiatry 70, 408-414.

Drago, F., Di Leo, F., and Giardina, L. (1999). Prenatal stress induces body weight deficit and behavioural alterations in rats: the effect of diazepam. Eur Neuropsychopharmacol 9, 239-245.

Drake, A.J., Walker, B.R., and Seckl, J.R. (2005). Intergenerational consequences of fetal programming by in utero exposure to glucocorticoids in rats. Am J Physiol Regul Integr Comp Physiol 288, R34-38.

Drevets, W.C. (2000). Functional anatomical abnormalities in limbic and prefrontal cortical structures in major depression. Prog Brain Res 126, 413-431.

Eastwood, S.L., and Harrison, P.J. (2005). Decreased expression of vesicular glutamate transporter 1 and complexin II mRNA in schizophrenia: further evidence for a synaptic pathology affecting glutamate neurons. Schizophr Res 73, 159-172.

Eastwood, S.L., Weickert, C.S., Webster, M.J., Herman, M.M., Kleinman, J.E., and Harrison, P.J. (2006). Synaptophysin protein and mRNA expression in the human hippocampal formation from birth to old age. Hippocampus 16, 645-654. 
Favaro, A., Tenconi, E., Ceschin, L., Zanetti, T., Bosello, R., and Santonastaso, P. (2011). In utero exposure to virus infections and the risk of developing anorexia nervosa. Psychol Med 41, 2193-2199.

Favaro, A., Tenconi, E., and Santonastaso, P. (2006). Perinatal factors and the risk of developing anorexia nervosa and bulimia nervosa. Arch Gen Psychiatry 63, 82-88.

Franklin, T.B., Russig, H., Weiss, I.C., Graff, J., Linder, N., Michalon, A., Vizi, S., and Mansuy, I.M. (2010). Epigenetic transmission of the impact of early stress across generations. Biol Psychiatry 68, 408-415.

Fujioka, T., Fujioka, A., Tan, N., Chowdhury, G.M., Mouri, H., Sakata, Y., and Nakamura, S. (2001). Mild prenatal stress enhances learning performance in the non-adopted rat offspring. Neuroscience 103, 301-307.

Fuster, J.M. (2001). The prefrontal cortex-an update: time is of the essence. Neuron 30, 319-333.

Geddes, J.R., and Lawrie, S.M. (1995). Obstetric complications and schizophrenia: a meta-analysis. Br J Psychiatry 167, 786-793.

Godfrey, K.M., and Barker, D.J. (2000). Fetal nutrition and adult disease. Am J Clin Nutr 71, 1344S-1352S.

Griffin, W.C., 3rd, Skinner, H.D., Salm, A.K., and Birkle, D.L. (2003). Mild prenatal stress in rats is associated with enhanced conditioned fear. Physiol Behav 79, 209-215.

Grizenko, N., Shayan, Y.R., Polotskaia, A., Ter-Stepanian, M., Joober, R. (2008). Relation of maternal stress during pregnancy to symptom severity and response to treatment in children withADHD. J Psychiatry Neurosci 33, 10-16.

Guo, A., Nappi, R.E., Criscuolo, M., Ficarra, G., Amram, A., Trentini, G.P., Petraglia, F., and Genazzani, A.R. (1993). Effect of chronic intermittent stress on rat pregnancy and postnatal development. Eur J Obstet Gynecol Reprod Biol 51, 41-45.

Hallett, M. (2001). Plasticity of the human motor cortex and recovery from stroke. Brain Res Brain Res Rev 36, 169-174.

Hassell, K.L. (2010). Population estimates of sickle cell disease in the U.S. Am J Prev Med 38, S512-521.

Holladay, S.D. (1999). Prenatal immunotoxicant exposure and postnatal autoimmune disease. Environ Health Perspect 107 Suppl 5, 687-691.

Horrigan, D.J., Horwitz, B.A., and Horowitz, J.M. (1997). Serotonergic modulation of hippocampal pyramidal cells in euthermic, cold-acclimated, and hibernating hamsters. Am J Physiol 273, R1291-1298.

Hosp, J.A., Luft, A.R. (2011). Cortical plasticity during motor learning and recovery after ischemic stroke. Neural Plast 2011, 871296.

Hosseini-Sharifabad, M., and Hadinedoushan, H. (2007). Prenatal stress induces learning deficits and is associated with a decrease in granules and CA3 cell dendritic tree size in rat hippocampus. Anat Sci Int 82, 211-217.

Huizink, A.C., Dick, D.M., Sihvola, E., Pulkkinen, L., Rose, R.J., and Kaprio, J. (2007). Chernobyl exposure as stressor during pregnancy and behaviour in adolescent offspring. Acta Psychiatr Scand 116, 438-446.

Hunter, S.K., Mendoza, J.H., D’Anna, K., Zerbe, G.O., McCarthy, L., Hoffman, C., Freedman, R., Ross, R.G. (2012) Antidepressants may mitigate the effects of prenatal maternal anxiety on infant auditory sensory gating. Am J Psychiatry 169; 616-624.

Hut, R.A., Van der Zee, E.A., Jansen, K., Gerkema, M.P., and Daan, S. (2002). Gradual reappearance of post-hibernation circadian rhythmicity correlates with numbers of 
vasopressin-containing neurons in the suprachiasmatic nuclei of European ground squirrels. J Comp Physiol B 172, 59-70.

Huttenlocher, P.R. (1984). Synapse elimination and plasticity in developing human cerebral cortex. Am J Ment Defic 88, 488-496.

Jensen, P.S., Mrazek, D., Knapp, P.K., Steinberg, L., Pfeffer, C., Schowalter, J., and Shapiro, T. (1997). Evolution and revolution in child psychiatry: ADHD as a disorder of adaptation. J Am Acad Child Adolesc Psychiatry 36, 1672-1679; discussion 1679-1681.

Julian, C.G., Vargas, E., Armaza, J.F., Wilson, M.J., Niermeyer, S., and Moore, L.G. (2007). High-altitude ancestry protects against hypoxia-associated reductions in fetal growth. Arch Dis Child Fetal Neonatal Ed 92, F372-377.

Kaiser, S., Kruijver, F.P., Straub, R.H., Sachser, N., and Swaab, D.F. (2003a). Early social stress in male Guinea-pigs changes social behaviour, and autonomic and neuroendocrine functions. J Neuroendocrinol 15, 761-769.

Kaiser, S., Kruijver, F.P., Swaab, D.F., and Sachser, N. (2003b). Early social stress in female guinea pigs induces a masculinization of adult behavior and corresponding changes in brain and neuroendocrine function. Behav Brain Res 144, 199-210.

Kaiser, S., and Sachser, N. (2009). Effects of prenatal social stress on offspring development pathology or adaptation? Curr Direct Psychol Sci 18, 118-121.

Kapoor, A., Kostaki, A., Janus, C., and Matthews, S.G. (2009). The effects of prenatal stress on learning in adult offspring is dependent on the timing of the stressor. Behav Brain Res 197, 144-149.

Khashan, A.S., Abel, K.M., McNamee, R., Pedersen, M.G., Webb, R.T., Baker, P.N., Kenny, L.C., and Mortensen, P.B. (2008). Higher risk of offspring schizophrenia following antenatal maternal exposure to severe adverse life events. Arch Gen Psychiatry 65, 146-152.

Kingston, D., Tough, S., and Whitfield, H. (2012). Prenatal and postpartum maternal psychological distress and infant development: a systematic review. Child Psychiatry Hum Dev 43, 683-714.

Kinney, D.K., Richards, R., Lowing, P.A., LeBlanc, D., Zimbalist, M.E., and Harlan, P. (2000). Creativity in offspring of schizophrenic and control parents: an adoption study. Creat Res J 13, 17-25.

Kinney, D.K., Munir, K.M., Crowley, D.J., and Miller, A.M. (2008). Prenatal stress and risk for autism. Neurosci Biobehav Rev 32, 1519-1532.

Knackstedt, M.K., Hamelmann, E., and Arck, P.C. (2005). Mothers in stress: consequences for the offspring. Am J Reprod Immunol 54, 63-69.

Koenig, J.I., Elmer, G.I., Shepard, P.D., Lee, P.R., Mayo, C., Joy, B., Hercher, E., and Brady, D.L. (2005). Prenatal exposure to a repeated variable stress paradigm elicits behavioral and neuroendocrinological changes in the adult offspring: potential relevance to schizophrenia. Behav Brain Res 156, 251-261.

Kolb, B., and Whishaw, I.Q. (1998). Brain plasticity and behavior. Annu Rev Psychol 49, 43-64.

Kwiatkowski, D.P. (2005). How malaria has affected the human genome and what human genetics can teach us about malaria. Am J Hum Genet 77, 171-192.

Laplante, D.P., Brunet, A., Schmitz, N., Ciampi, A., and King, S. (2008). Project Ice Storm: prenatal maternal stress affects cognitive and linguistic functioning in 51 /2-year-old children. J Am Acad Child Adolesc Psychiatry 47, 1063-1072. 
Lee, P.R., Brady, D.L., Shapiro, R.A., Dorsa, D.M., and Koenig, J.I. (2007). Prenatal stress generates deficits in rat social behavior: Reversal by oxytocin. Brain Res 1156, 152-167.

Lehmann, J., Stohr, T., and Feldon, J. (2000). Long-term effects of prenatal stress experiences and postnatal maternal separation on emotionality and attentional processes. Behav Brain Res 107, 133-144.

Lemaire, V., Koehl, M., Le Moal, M., and Abrous, D.N. (2000). Prenatal stress produces learning deficits associated with an inhibition of neurogenesis in the hippocampus. Proc Natl Acad Sci U S A 97, 11032-11037.

Leuba, G., and Rabinowicz, T. (1979). Long-term effects of postnatal undernutrition and maternal malnutrition on mouse cerebral cortex. II. Evolution of dendritic branchings and spines in the visual region. Exp Brain Res 37, 299-308.

Li, B., Piriz, J., Mirrione, M., Chung, C., Proulx C.D., Schulz, D., Henn, F., and Malinow, R. (2011). Synaptic potentiation onto habenula neurons in the learned haplessness model of depression. Nature 470, 535-539.

Loomans, E.M., van der Stelt, O., van Eijsden, M., Gemke, R.J., Vrijkotte, T., and den Bergh, B.R. (2011) Antenatal maternal anxiety is associated with problem behaviour at age five. Early Hum Dev 87, 565-570.

Lui, C.C., Wang, J.Y., Tain, Y.L., Chen, Y.C., Chang, K.A., Lai, M.C., and Huang, L.T. (2011). Prenatal stress in rat causes long-term spatial memory deficit and hippocampus MRI abnormality: differential effects of postweaning enriched environment. Neurochem Int 58, 434-441.

Lumey, L.H., Stein, A.D., and Susser, E. (2011). Prenatal famine and adult health. Annu Rev Public Health 32, 237-262.

Lyons, D.M., Afarian, H., Schatzberg, A.F., Sawyer-Glover, A., and Moseley, M.E. (2002). Experience-dependent asymmetric variation in primate prefrontal morphology. Behav Brain Res 136, 51-59.

Maccani, M.A., Avissar-Whiting, M., Banister, C.E., McGonnigal, B., Padbury, J.F., and Marsit, C.J. (2010). Maternal cigarette smoking during pregnancy is associated with downregulation of miR-16, miR-21, and miR-146a in the placenta. Epigenetics 5, 583-589.

Maccari, S., Piazza, P.V., Kabbaj, M., Barbazanges, A., Simon, H., and Le Moal, M. (1995). Adoption reverses the long-term impairment in glucocorticoid feedback induced by prenatal stress. J Neurosci 15, 110-116.

Machon, R.A., Mednick, S.A., and Huttunen, M.O. (1997). Adult major affective disorder after prenatal exposure to an influenza epidemic. Arch Gen Psychiatry 54, 322-328.

Malaspina, D., Corcoran, C., Kleinhaus, K.R., Perrin, M.C., Fennig, S., Nahon, D., Friedlander, Y., and Harlap, S. (2008). Acute maternal stress in pregnancy and schizophrenia in offspring: a cohort prospective study. BMC Psychiatry 8, 71.

Markham, J.A., Taylor, A.R., Taylor, S.B., Bell, D.B., and Koenig, J.I. (2010). Characterization of the cognitive impairments induced by prenatal exposure to stress in the rat. Front Behav Neurosci 4, 173.

Mastorci, F., Vicentini, M., Viltart, O., Manghi, M., Graiani, G., Quaini, F., Meerlo, P., Nalivaiko, E., Maccari, S., and Sgoifo, A. (2009). Long-term effects of prenatal stress: changes in adult cardiovascular regulation and sensitivity to stress. Neurosci Biobehav Rev 33, 191-203.

McBride, T., Arnold, S.E., and Gur, R.C. (1999). A comparative volumetric analysis of the 
prefrontal cortex in human and baboon MRI. Brain Behav Evol 54, 159-166.

Mednick, S.A., Machon, R.A., Huttunen, M.O., and Bonett, D. (1988). Adult schizophrenia following prenatal exposure to an influenza epidemic. Arch Gen Psychiatry 45, 189-192.

Meneses, A., and Perez-Garcia, G. (2007). 5-HT(1A) receptors and memory. Neurosci Biobehav Rev 31, 705-727.

Mick, E., Biederman, J., Prince, J., Fischer, M.J., and Faraone, S.V. (2002). Impact of low birth weight on attention-deficit hyperactivity disorder. J Dev Behav Pediatr 23, 16-22.

Mincheva-Nilsson, L., and Baranov, V. (2010). The role of placental exosomes in reproduction. Am J Reprod Immunol 63, 520-533.

Mitchell, P.S., Parkin, R.K., Kroh, E.M., Fritz, B.R., Wyman, S.K., Pogosova-Agadjanyan, E.L., Peterson, A., Noteboom, J., O'Briant, K.C., Allen, A., Lin, D.W., Urban, N., Drescher, C.W., Knudsen, B.S., Stirewalt, D.L., Gentleman, R., Vessella, R.L., Nelson, P.S., Martin, D.B., and Tewari, M. (2008). Circulating microRNAs as stable blood-based markers for cancer detection. Proc Natl Acad Sci U S A 105, 10513-10518.

Mitterauer, B.J. (2011). Possible role of glia in cognitive impairment in schizophrenia. CNS Neurosci Ther 17, 333-344.

Miura, K., Miura, S., Yamasaki, K., Higashijima, A., Kinoshita, A., Yoshiura, K., and Masuzaki, H. (2010) Identification of pregnancy-associated microRNAs in maternal plasma. Clin Chem 56, 1767-1771.

Moises, H.W., and Gottesman, I.I. (2004). Does glial asthenia predispose to schizophrenia? Arch Gen Psychiatry 61, 1170.

Monteleone, P., Martiadis, V., and Maj, M. (2011). Circadian rhythms and treatment implications in depression. Prog Neuropsychopharmacol Biol Psychiatry 35, 1569-1574.

Morgan, C.P., and Bale, T.L. (2011). Early prenatal stress epigenetically programs dysmasculinization in second-generation offspring via the paternal lineage. J Neurosci 31, 11748-11755.

Morgan, H.D., Sutherland, H.G., Martin, D.I., and Whitelaw, E. (1999). Epigenetic inheritance at the agouti locus in the mouse. Nat Genet 23, 314-318.

Mouillet, J.F., Chu, T., Hubel, C.A., Nelson, D.M., Parks, W.T., and Sadovsky, Y. (2010). The levels of hypoxia-regulated microRNAs in plasma of pregnant women with fetal growth restriction. Placenta 31, 781-784.

Murmu, M.S., Salomon, S., Biala, Y., Weinstock, M., Braun, K., and Bock, J. (2006). Changes of spine density and dendritic complexity in the prefrontal cortex in offspring of mothers exposed to stress during pregnancy. Eur J Neurosci 24, 1477-1487.

Musselman, D.L., Betan, E., Larsen, H., and Phillips, L.S. (2003). Relationship of depression to diabetes types 1 and 2: epidemiology, biology, and treatment. Biol Psychiatry 54, 317-329.

Mychasiuk, R., Gibb, R., and Kolb, B. (2012). Prenatal stress alters dendritic morphology and synaptic connectivity in the prefrontal cortex and hippocampus of developing offspring. Synapse 66, 308-314.

Naumenko, V.S., Tkachev, S.E., Kulikov, A.V., Semenova, T.P., Amerhanov, Z.G., Smirnova, N.P., and Popova, N.K. (2008). The brain 5-HT1A receptor gene expression in hibernation. Genes Brain Behav 7, 300-305.

Nedergaard, M., and Dirnagl, U. (2005). Role of glial cells in cerebral ischemia. Glia 50, 281-286. 
New, J., Krasnow, M.M., Truxaw, D., and Gaulin, S.J. (2007). Spatial adaptations for plant foraging: women excel and calories count. Proc Biol Sci 274, 2679-2684.

Niederhofer, H. (2004). A longitudinal study: some preliminary results of association of prenatal maternal stress and fetal movements, temperament factors in early childhood and behavior at age 2 years. Psychol Rep 95, 767-770.

O'Connor, T.G., Heron, J., and Glover, V.; Alspac Study Team. (2002). Antenatal anxiety predicts child behavioral/emotional problems independently of postnatal depression. $J$ Am Acad Child Adolesc Psychiatry 41, 1470-1477.

Painter, R.C., Osmond, C., Gluckman, P., Hanson, M., Phillips, D.I., and Roseboom, T.J. (2008). Transgenerational effects of prenatal exposure to the Dutch famine on neonatal adiposity and health in later life. BJOG 115, 1243-1249.

Petanjek, Z., Judas, M., Simic, G., Rasin, M.R., Uylings, H.B., Rakic, P., Kostovic, I. (2011). Extraordinary neoteny of synaptic spines in the human prefrontal cortex. Proc Natl Acad Sci USA 108, 13281-13286.

Phillips, D.I., and Jones, A. (2006). Fetal programming of autonomic and HPA function: do people who were small babies have enhanced stress responses? J Physiol 572, 45-50.

Pietrini, F., Castellini, G., Ricca, V., Polito, C., Pupi, A., and Faravelli, C. (2011). Functional neuroimaging in anorexia nervosa: a clinical approach. Eur Psychiatry 26, 176-182.

Preti, A., Cardascia, L., Zen, T., Pellizzari, P., Marchetti, M., Favaretto, G., and Miotto, P. (2000). Obstetric complications in patients with depression--a population-based case-control study. J Affect Disord 61, 101-106.

Rakic, P., Bourgeois, J.P., Eckenhoff, M.F., Zecevic, N., and Goldman-Rakic, P.S. (1986). Concurrent overproduction of synapses in diverse regions of the primate cerebral cortex. Science 232, 232-235.

Rassoulzadegan, M., Grandjean, V., Gounon, P., Vincent, S., Gillot, I., and Cuzin, F. (2006). RNA-mediated non-mendelian inheritance of an epigenetic change in the mouse. Nature 441, 469-474.

Rechavi, O., Minevich, G., and Hobert, O. (2011). Transgenerational inheritance of an acquired small RNA-based antiviral response in C. elegans. Cell 147, 1248-1256.

Rice, F., Harold, G.T., Boivin, J., van den Bree, M., Hay, D.F., and Thapar, A. (2010). The links between prenatal stress and offspring development and psychopathology: disentangling environmental and inherited influences. Psychol Med 40, 335-345.

Rieger, M., Pirke, K.M., Buske-Kirschbaum, A., Wurmser, H., Papousek, M., and Hellhammer, D.H. (2004). Influence of stress during pregnancy on HPA activity and neonatal behavior. Ann $N$ Y Acad Sci 1032, 228-230.

Rilling, J,K. (2006). Human and nonhuman primate brains: are they allometrically scaled versions of the same design? Evol Anthropol 15, 65-77

Rodriguez, A., and Bohlin, G. (2005). Are maternal smoking and stress during pregnancy related to ADHD symptoms in children? J Child Psychol Psychiatry 46, 246-254.

Ronald, A., Pennell, C.E., and Whitehouse, A.J. (2011). Prenatal maternal stress associated with ADHD and autistic traits in early childhood. Front Psychol 1, 223.

Rothermundt, M., Ohrmann, P., Abel, S., Siegmund, A., Pedersen, A., Ponath, G., Suslow, T., Peters, M., Kaestner, F., Heindel, W., Arolt, V., and Pfleiderer, B. (2007). Glial cell activation in a subgroup of patients with schizophrenia indicated by increased S100B serum concentrations and elevated myo-inositol. Prog Neuropsychopharmacol Biol Psychiatry 31, 361-364. 
Salomon, S., Bejar, C., Schorer-Apelbaum, D., and Weinstock, M. (2011). Corticosterone mediates some but not other behavioural changes induced by prenatal stress in rats. $J$ Neuroendocrinol 23, 118-128.

Sayed, D., and Abdellatif, M. (2011). MicroRNAs in development and disease. Physiol Rev 91, 827-887.

Schmale A.H., and Engel, G.L. (1975). The role of conservation-withdrawal in depressive reactions. In: Benedek, T., Anthony, E.J., eds. Depression and Human Existence Boston: Little Brown \& Co. 183-198.

Seidman, L.J., Valera, E.M., and Makris, N. (2005). Structural brain imaging of attention-deficit/hyperactivity disorder. Biol Psychiatry 57, 1263-1272.

Semendeferi, K., Lu, A., Schenker, N., and Damasio, H. (2002). Humans and great apes share a large frontal cortex. Nat Neurosci 5, 272-276.

Shaw, P., Eckstrand, K., Sharp, W., Blumenthal, J., Lerch, J.P., Greenstein, D., Clasen, L., Evans, A., Giedd, J., and Rapoport, J.L. (2007). Attention-deficit/hyperactivity disorder is characterized by a delay in cortical maturation. Proc Natl Acad Sci U S A 104, 19649-19654.

Shelton, J.F., Tancredi, D.J., and Hertz-Picciotto, I. (2010). Independent and dependent contributions of advanced maternal and paternal ages to autism risk. Autism Res 3, 30-39.

Smaers, J.B., Steele, J., Case, C.R., Cowper, A., Amunts, K., and Zilles, K. (2011). Primate prefrontal cortex evolution: human brains are the extreme of a lateralized ape trend. Brain Behav Evol 77, 67-78.

Son, G.H., Geum, D., Chung, S., Kim, E.J., Jo, J.H., Kim, C.M., Lee, K.H., Kim, H., Choi, S., Kim, H.T., Lee, C.J., and Kim, K. (2006). Maternal stress produces learning deficits associated with impairment of NMDA receptor-mediated synaptic plasticity. $J$ Neurosci 26, 3309-3318.

Soumiya, H., Fukumitsu, H., and Furukawa, S. (2011). Prenatal immune challenge compromises the normal course of neurogenesis during development of the mouse cerebral cortex. $J$ Neurosci Res 89, 1575-1585.

Stephan, H., Baron, G., and Frahm, H.D. (1988). Comparative size of brains and brain components. In: Steklis, H.D., Erwin, J., eds, Comparative Primate Biology Vol. 4, New York: Alan R Liss. 1-38.

Susser, E., Neugebauer, R., Hoek, H.W., Brown, A.S., Lin, S., Labovitz, D., and Gorman, J.M. (1996). Schizophrenia after prenatal famine. Further evidence. Arch Gen Psychiatry 53, 25-31.

Sutherland, H.G., Kearns, M., Morgan, H.D., Headley, A.P., Morris, C., Martin, D.I., and Whitelaw, E. (2000). Reactivation of heritably silenced gene expression in mice. Mamm Genome 11, 347-355.

Szuran, T., Zimmermann, E., and Welzl, H. (1994). Water maze performance and hippocampal weight of prenatally stressed rats. Behav Brain Res 65, 153-155.

Teffer, K., and Semendeferi, K. (2012). Human prefrontal cortex: evolution, development, and pathology. Prog Brain Res 195, 191-218.

Thase, M.E. (1998). Depression, sleep, and antidepressants. J Clin Psychiatry 59 Suppl 4, 55-65.

Valadi, H., Ekstrom, K., Bossios, A., Sjostrand, M., Lee, J.J., and Lotvall, J.O. (2007). Exosome-mediated transfer of mRNAs and microRNAs is a novel mechanism of genetic exchange between cells. Nat Cell Biol 9, 654-659. 
Vallee, M., MacCari, S., Dellu, F., Simon, H., Le Moal, M., and Mayo, W. (1999). Long-term effects of prenatal stress and postnatal handling on age-related glucocorticoid secretion and cognitive performance: a longitudinal study in the rat. Eur J Neurosci 11, 2906-2916.

Vallee, M., Mayo, W., Dellu, F., Le Moal, M., Simon, H., and Maccari, S. (1997). Prenatal stress induces high anxiety and postnatal handling induces low anxiety in adult offspring: correlation with stress-induced corticosterone secretion. J Neurosci 17, 2626-2636.

van Os, J., and Selten, J.P. (1998). Prenatal exposure to maternal stress and subsequent schizophrenia. The May 1940 invasion of The Netherlands. $\mathrm{Br} J$ Psychiatry 172, 324-326.

Verdoux, H., Geddes, J.R., Takei, N., Lawrie, S.M., Bovet, P., Eagles, J.M., Heun, R., McCcreadie, R.G., McNeil, T.F., O'Callaghan, E., Stober, G., Willinger, M.U., Wright, P., and Murray, R.M. (1997). Obstetric complications and age at onset in schizophrenia: an international collaborative meta-analysis of individual patient data. Am J Psychiatry 154, 1220-1227.

Vrekoussis, T., Kalantaridou, S.N., Mastorakos, G., Zoumakis, E., Makrigiannakis, A., Syrrou, M., Lavasidis, L.G., Relakis, K., and Chrousos, G.P. (2010) The role of stress in female reproduction and pregnancy: an update. Ann N Y Acad Sci 1205, 69-75.

Waddington, C.H. (1953). Genetic assimilation of an acquired character. Evolution 7, 118-126.

Wadhwa, P.D., Sandman, C.A., Porto, M., Dunkel-Schetter, C., and Garite, T.J. (1993). The association between prenatal stress and infant birth weight and gestational age at birth: a prospective investigation. Am J Obstet Gynecol 169, 858-865.

Wakshlak, A., and Weinstock, M. (1990). Neonatal handling reverses behavioral abnormalities induced in rats by prenatal stress. Physiol Behav 48, 289-292.

Walker, A.K., Hawkins, G., Sominsky, L., and Hodgson, D.M. (2012). Transgenerational transmission of anxiety induced by neonatal exposure to lipopolysaccharide: Implications for male and female germ lines. Psychoneuroendocrinology 37, 1320-1335.

Wehmer, F., Porter, R.H., and Scales, B. (1970). Pre-mating and pregnancy stress in rats affects behaviour of grandpups. Nature 227, 622.

Weinberger, D.R., Aloia, M.S., Goldberg, T.E., and Berman, K.F. (1994). The frontal lobes and schizophrenia. J Neuropsychiatry Clin Neurosci 6, 419-427.

Weinstock, M., Matlina, E., Maor, G.I., Rosen, H., and McEwen, B.S. (1992). Prenatal stress selectively alters the reactivity of the hypothalamic-pituitary adrenal system in the female rat. Brain Res 595, 195-200.

Weinstock, M. (2008). The long-term behavioural consequences of prenatal stress. Neurosci Biobehav Rev 32, 1073-1086.

Winstanley, C.A., Chudasama, Y., Dalley, J.W., Theobald, D.E., Glennon, J.C., and Robbins, T.W. (2003). Intra-prefrontal 8-OH-DPAT and M100907 improve visuospatial attention and decrease impulsivity on the five-choice serial reaction time task in rats. Psychopharmacology (Berl) 167, 304-314.

World Health Organization (2000). Cross-national comparisons of the prevalences and correlates of mental disorders. WHO International Consortium in Psychiatric Epidemiology. Bull World Health Organ 78, 413-426.

Wood, J.N., and Grafman, J. (2003). Human prefrontal cortex: processing and representational perspectives. Nat Rev Neurosci 4, 139-147.

Woodcock, A., Lowe, L.A., Murray, C.S., Simpson, B.M., Pipis, S.D., Kissen, P., Simpson, A., and Custovic, A.; NAC Manchester Asthma and Allergy Study Group. (2004). Early life 
environmental control: effect on symptoms, sensitization, and lung function at age 3 years. Am J Respir Crit Care Med 170, 433-439.

Yaka, R., Salomon, S., Matzner, H., and Weinstock, M. (2007). Effect of varied gestational stress on acquisition of spatial memory, hippocampal LTP and synaptic proteins in juvenile male rats. Behav Brain Res 179, 126-132.

Yehuda, R., and Bierer, L.M. (2008). Transgenerational transmission of cortisol and PTSD risk. Prog Brain Res 167, 121-135.

Yu, E.Z., Hallenbeck, J,M., Cai, D., and McCarron, R,M. (2002). Elevated arylalkylamine-N-acetyltransferase (AA-NAT) gene expression in medial habenular and suprachiasmatic nuclei of hibernating ground squirrels. Brain Res Mol Brain Res 102, 9-17.

Zambrano, E., Martinez-Samayoa, P.M., Bautista, C.J., Deas, M., Guillen, L., Rodriguez-Gonzalez, G.L., Guzman, C., Larrea, F., and Nathanielsz, P.W. (2005). Sex differences in transgenerational alterations of growth and metabolism in progeny (F2) of female offspring (F1) of rats fed a low protein diet during pregnancy and lactation. $J$ Physiol 566, 225-236. 